\title{
Socio-demographic and clinical predictors of health-related quality of life in patients after myocardial infarction
}

\author{
Sylwia Krzemińska', Ewelina Bąk², Ewa Król ${ }^{3}$, Marta Arendarczyk1 , Adriana Borodzicz¹ \\ ${ }^{1}$ Department of Clinical Nursing, Faculty of Health Sciences, Medical University, Wrocław, Poland \\ 2 University of Bielsko-Biała, Faculty of Health Sciences, Poland \\ 3 /I Cardiac Department, American Heart of Poland, Bielsko-Biała, Poland
}

Krzemińska S, Bąk E, Król E, Arendarczyk M, Borodzicz A. Socio-demographic and clinical predictors of health related quality of life in patients after myocardial infarction. J Pre-Clin Clin Res. 2019; 13(1): 13-18. doi: 10.26444/jpccr/102758

\begin{abstract}
Introduction. Acute coronary syndrome is associated with a reduction in the patients' own perception of their quality of life (QoL). QoL is an important measure of the effectiveness of treatment; however, some of the predictors may be associated with a lower QoL assessment. The evaluation of QoL of patients after myocardial infarctions takes into consideration the socio-demographic and clinical predictors which can affect the level of health-related QoL

Objective The aim of this study is to determine which socio-demographic and clinical factors have a positive or negative impact on QoL.

Materials and method. The study included 100 patients of the American Heart of Poland Clinic in Bielsko-Biała who had undergone ST-myocardial infarction. For the purpose of the study, the following instruments were used: demographic data sheet, the Nottingham Health Profile questionnaire, and items regarding clinical variables: gender, age, education, marital status, occupational activity, blood pressure and heart rate, BMI, physical activity.

Results. Comparative analysis of QoL, depending on the selected variables, revealed statistically significant differences among respondents with reference to age. People above the age of 85 showed the lowest rating of QoL in domains: Energy $(\mathrm{NHP}=100)$, Pain (80.3), and Mobility restriction (78.7). People with primary and vocational education rated their QoL worse than those with secondary and high education. The lowest QoL was typical of the single and widowers, obese and physical inactive people.

Conclusions. Multivariate analysis proved the influence of socio-demographic and clinical factors on individual NHP domains. Significant independent determinants of lower QoL were old age and BMI, whereas staying in a relationship, physical activity and occupational inactivity were important determinants of higher QoL scores.
\end{abstract}

\section{Key words}

quality of life, myocardial Infarction, socio-demographic and clinical predicators

\section{INTRODUCTION}

Diseases of the circulatory system are the most important health-related problem of modern society [1]. The development of civilization significantly commits to the increase of the incidence of hypertensive disease, arrhythmias, vascular diseases, arteriosclerosis, and acute coronary syndrome. Coronary heart disease and myocardial infarction related to it have become a special and alarming problem for public health in Poland in recent years. Cardiac events are the main cause of deaths in Polish society. Diseases of the cardiovascular system, including myocardial infarction, occur as a result of the impact of many factors [2].

There are modifiable predictors affecting the quality of life (QoL): smoking [3], arterial hypertension (which increases the risk of the development of heart failure, stroke and kidney disease) [4], hypercholesterolaemia (increase in the concentration of cholesterol by 10\%) [5], low level of physical activity (regular undertaking of moderate physical exertion allows for reducing the risk of the ischemic disease by $30-$ 50\%) [6], metabolic syndromes and diabetes [7], nd obesity [8].

Address for correspondence: Ewelina Bąk, University of Bielsko-Biała, Faculty of Health Sciences, Poland

E-mail: ewelina.bak76@wp.pl)

Received: 1 December 2018; accepted: 11 January 2019; first published: 21 March 2019
Myocardial infarction and the subsequent chronic period of convalescence, as well as the restrictions resulting from it affect the QoL of the patient. If we understand QoL as the patient's physical, mental and social ability to function, conditioned by his/her health status, then in the case of patients with circulatory system diseases this quality is low. QoL is not only a subjective evaluation of the health status expressed by a certain physical capacity and the absence of coronary pain or other disease symptoms, but it is also the return to professional activity, job satisfaction, social activity, having a hobby, mutual relations with family and friends, intellectual and cognitive functions, the sense of self-control and self-trust, sexual activity, coping in various situations, and the mood and satisfaction with life [9].

\section{MATERIALS AND METHOD}

The research was carried out from 1 December 2015 - 1 March 2016 in patients of the American Heart of Poland Clinic in Bielsko-Biała who underwent myocardial infarction. 117 patients were included in the study. The final sample included 100 participants for an overall response rate of $85 \%$.

The management of the clinic gave their consent for carrying out the study. Each patient who agreed to participate 
was informed about the aim, anonymity of the questionnaire, and how to complete it.

The method used for carrying out the research was a diagnostic poll. The research tools were the Nottingham Health Profile questionnaire and a demographic survey of own authorship. Consent was obtained for applying the questionnaire. The Nottingham Health Profile questionnaire was used for measuring the assessment of QoL. It consists of two parts. The first part refers to currently existing problems related to physical, mental and social functioning connected with health status. It includes 38 short statements referring to 6 domains, dimensions of the subjective health status, such as: energy level, pain, emotional reactions, sleep, social isolation and physical mobility. The second part of the questionnaire refers to the influence of the current health status on 7 areas of life: work (intensity and the remuneration), looking after the home (cleaning, cooking, jobs around the house), social life (seeing friends, going out together), home life, sex life, interests and hobbies, and spending free time (holidays, vacation). For each question, the respondents provided an answer: "yes" or "no". The results of the examinations were calculated separately for each of the 6 domains in the first part of the questionnaire, and the 7 areas of life in the second part. The results for each of the domains could range from 0 - 100. The higher the score, the worse QoL in the investigated area [10]. The applied research tool has been standardized, i.e. its reliability and accuracy have been tested on larger research groups [11] (hence a high degree of the credibility of the studies), and the tool also adapted by K. Wrześniewski [12] to Polish conditions.

Brief information regarding the research group was attached to the performed studies. This included information such as the age, gender, place of residence, education, marital status, professional activity and type of work performed. Information regarding clinical characteristics were also been included in the study. They referred to smoking cigarettes, arterial blood pressure, cholesterol level, diet and physical activity. The data collected by means of these questions allowed for characterizing the research group.

All procedures performed in the study involving human participants were in accordance with the standards of the Ethical Committee and with the 1964 Declaration of Helsinki.

Statistical methods. Statistical analysis were carried out with the programme Statistica v.10 (StatSoft Polska Company).

The research tools applied for statistical calculations were the Kruskal-Wallis Test, Spearman's Rank Correlation Coefficient Test and the Mann-Whitney U Test. The level of significance applied during statistical inference was a $=0.05$. Basic statistical data were calculated, i.e. average with standard deviation for the 6 domains of the NHP questionnaire (energy, pain, emotional reaction, sleep disorders, social isolation, restricted mobility) taking into account socio-demographic and clinical data. Instrument reliability (internal consistency) was assessed using Cronbach alpha (ac), result -0.91 .

Independent groups without univariate components were compared by Mann-Whitney test ( 2 groups) and by Kruskal-Wallis test (3 or more groups). Groups in which Kruskal-Wallis test showed a difference between results with an average result of NHP questionnaire were analyzed by Dunne post-hoc test to identify between statistically significant groups.

Table 1. Demographic and clinical characteristics of the studied group Gender $(\mathbf{p}=\mathbf{0 . 0 7 1 8 )} \quad \%$

\begin{tabular}{ll}
\hline Female & $41.0 \%$ \\
\hline Male & $59.0 \%$ \\
\hline
\end{tabular}

Age $(\mathrm{p}=\mathbf{0 . 0 0 0 0 )} \quad \%$

\begin{tabular}{ll}
\hline $45-54$ & $15.2 \%$ \\
\hline $55-64$ & $34.3 \%$ \\
\hline
\end{tabular}

\begin{tabular}{ll}
\hline $55-64$ & $34.3 \%$ \\
\hline
\end{tabular}

\begin{tabular}{ll}
\hline $65-74$ & $31.3 \%$ \\
\hline $75-84$ & $17.2 \%$ \\
\hline
\end{tabular}

\begin{tabular}{lc}
$75-84$ & $17.2 \%$ \\
\hline $85-94$ & $2.0 \%$ \\
\hline
\end{tabular}

Education $(\mathbf{p}=\mathbf{0 . 0 0 1 2 )} \quad \%$

\begin{tabular}{lc}
\hline Primary & $10.0 \%$ \\
\hline Voctional & $37.0 \%$ \\
\hline Secondary & $30.0 \%$ \\
\hline Higher & $23.0 \%$ \\
\hline Maritial status (p=0.0003) & $\%$ \\
\hline Single & $41.0 \%$ \\
\hline In relationship & $59.0 \%$ \\
\hline Occupational activity $\mathbf{(} \mathbf{p}=\mathbf{0 . 0 1 6 4 )}$ & $\%$ \\
\hline Unemployed & $62.0 \%$ \\
\hline Working & $38.0 \%$ \\
\hline Blood pressure and heart rythm control $\mathbf{( p = 0 . 0 0 5 )}$ & $\%$ \\
\hline Everyday self- control & $50.5 \%$ \\
\hline Rarely self-control & $30.3 \%$ \\
\hline
\end{tabular}

\begin{tabular}{ll}
\hline During an appointment at the doctor & $30.3 \%$ \\
\hline
\end{tabular}

Higher level of cholesterol $(\mathbf{p}=\mathbf{0 . 0 0 0 0 )} \quad \%$

\begin{tabular}{ll}
\hline No & $29.0 \%$ \\
\hline Yes & $71.0 \%$
\end{tabular}

Level of cholesterol $(\mathrm{p}=\mathbf{0 . 0 0 1 7 )} \quad \%$

$100-149 \quad 10.0 \%$

\begin{tabular}{ll}
$150-199$ & $10.0 \%$ \\
\hline
\end{tabular}

\begin{tabular}{lr}
\hline $200-249$ & $30.0 \%$ \\
\hline$>250$ & $39.0 \%$ \\
\hline
\end{tabular}

\begin{tabular}{cc}
\hline$>250$ & $39.0 \%$ \\
\hline Cholesterol level control $(\mathbf{p}=\mathbf{0 . 0 0 5 1})$ & $\%$ \\
\hline
\end{tabular}

\begin{tabular}{cc}
\hline Cholesterol level control $(\mathbf{p}=\mathbf{0 . 0 0 5 1 )}$ & $\%$ \\
\hline Irregular & $64.0 \%$ \\
\hline Regular & $36.0 \%$ \\
\hline Using drugs to reduce cholesterol level $\mathbf{(} \mathbf{p}=\mathbf{0 . 0 7 1 8})$ & $\%$ \\
\hline No & $41.0 \%$ \\
\hline Yes & $59.0 \%$ \\
\hline BMI ( $\mathbf{p}=\mathbf{0 . 0 0 0 6 )}$ & $\%$ \\
\hline$<=30$ & $67.0 \%$ \\
\hline$>30$ & $33.0 \%$ \\
\hline Kind of diet $\mathbf{(}=\mathbf{0 . 0 0 0 0 )}$ & $\%$ \\
\hline Diabetic diet & $17.0 \%$ \\
\hline Low-salt diet & $0.0 \%$ \\
\hline Low-fat diet & $38.0 \%$ \\
\hline Physical activity $(\mathbf{p}=\mathbf{0 . 0 0 0 8})$ & $\%$ \\
\hline Sedentary lifestyle & $23.0 \%$ \\
\hline Mixed lifestyle & $51.0 \%$ \\
\hline Active lifestyle & $26.0 \%$ \\
\hline Hypertension $(\mathbf{p}=\mathbf{0 . 0 0 0 0 )}$ & $\%$ \\
\hline No & $14.0 \%$ \\
\hline Yes & $86.0 \%$ \\
\hline
\end{tabular}




\section{RESULTS}

On the basis of the obtained results it was possible to state that the level of impairment of the particular vital functions among patients after a myocardial infarction in particular domains were as follows: the highest result was obtained for the domain energy (47.7) and sleep disorders (45.6). Further domains in which problems occur were physical mobility limitations (34.1) and emotional reactions (33.4). The lowest impairment occurred in the domain of pain (25.8) and social isolation (22.5) (Tab. 2).

Table 2. Level of impairment of particular vital functions according to the NHP questionnaire in the studied group

\begin{tabular}{lcccccc}
\hline & $\begin{array}{c}\text { Energy } \\
(\mathrm{NHP})\end{array}$ & $\begin{array}{c}\text { Pain } \\
(\mathrm{NHP})\end{array}$ & $\begin{array}{c}\text { Emotional } \\
\text { reaction } \\
(\mathrm{NHP})\end{array}$ & $\begin{array}{c}\text { Sleep } \\
\text { disorders } \\
(\mathrm{NHP})\end{array}$ & $\begin{array}{c}\text { Social } \\
\text { isolation } \\
(\mathrm{NHP})\end{array}$ & $\begin{array}{c}\text { Mobility } \\
\text { restrictions } \\
(\mathrm{NHP})\end{array}$ \\
\hline $\mathrm{N}$ & 100 & 100 & 100 & 100 & 100 & 100 \\
\hline Mean & 47.7 & 25.8 & 33.4 & 45.6 & 22.5 & 34.1 \\
\hline SD & 39.8 & 28.0 & 28.2 & 38.5 & 29.0 & 26.7 \\
\hline Min & 0.0 & 0.0 & 0.0 & 0.0 & 0.0 & 0.0 \\
\hline Max & 100.0 & 100.0 & 100.0 & 100.0 & 79.9 & 87.4 \\
\hline
\end{tabular}

In order to compare independent groups with non-normal distributions, the Mann-Whitney test was used - in the case of comparisons between 2 groups and the Kruskal-Wallis test - in the case of comparisons of 3 or more groups. In the case where the Kruskal-Wallis test showed differences between the average NHP scores within the groups, in the next step, posthoc tests (Dunn's test) were carried out to discover between which groups statistically significant differences exist.

On the basis of the obtained results it ws not possible to conclude that the gender of the patients affected impairment of the areas of life measured using the NHP questionnaire.

For age, significant correlations were obtained in case of each of the 6 domains of the NHP questionnaire. The obtained interdependences had the character of a positive correlation, which means that the older the person, the higher (by average) the level of impairment of each of the 6 domains of life measured using the NHP questionnaire. Education did not affect social isolation, but for the remaining subscales of the NHP, significant relations were demonstrated. The mean values indicated that the highest level of impairment for 5 subscales occurred in the group of people with primary education and vocational education, whereas the lowest level of impairment of the 6 areas of life occurred in the group of people with higher education (Tab. 3)

Marital status affected all the life domains. In the case of emotional reactions, the biggest problems occurred in the group of unmarried men/women. In the remaining 5 subscales, the biggest problems occurred in the case of widowers.

Professional activity significantly affected all areas of life measured using the subscales of the NHP. The mean values for the subscales allowed the conclusion that a higher level of impairment in all the 6 areas of life occurred in the group of professionally inactive people.

Continuous controlling of the heart rate and blood pressure did not affect only sleep disruptions; for the remaining 5 subscales of the NHP, significant relations were observed. In these subscales, the biggest problems in the 5 life domains occurred in the group of people who had their heart rate and blood pressure checked only during controls performed by the physician (Tab. 3).

BMI was a factor significantly affecting each of the 6 analyzed domains of life. The obtained correlations were positive, which allowed the conclusion that the higher the BMI indicator, the bigger (by average) the problems in each of the 6 domains of life.

Physical activity influenced each of the 6 life domains. The mean values allowed the conclusion that the highest level of impairment of each of the 6 life domains occurred in the group of people leadings a sedentary lifestyle.

The BMI indicator did not influence only the problems related to hobbies and interests; the 6 remaining areas of life depended on the BMI indicator. The problems in these 6 areas were typical for people with a higher BMI indicator (Tab. 3).

A multiple linear regression model was constructed for each of the 6 NHP domains under consideration, which were dependent variables. As independent variables for the analysis, all socio-demographic (age, education, marital status, and professional activity) and clinical factors (heart rate and pressure control, BMI and physical activity) that were statistically significant in previous analyzes, were qualified. Because gender did not differentiate NHP data, this factor was not included in the multiple regression model (Tab. 4).

In multiple linear regression models, the influence of age on the emotional reaction domain $(\beta=-0.83 ; \mathrm{p}=0.0146)$ was noted, which means that higher age was an influence for higher QoL, but in domain mobility restrictions $(\beta=0.88$; $\mathrm{p}=0.002$ ), a lower QoL.

Another statistically important independent predictor was marital status. A correlation existed between being in a relationship and QoL in domains: emotional reaction $(\beta=-$ 16.34; $\mathrm{p}=0.0061)$, sleep disorders $(\beta=-18.43 ; \mathrm{p}=0.0389)$, and social isolation $(\beta=-35.88 ; \mathrm{p}<0.0001)$. QoL was higher for people in a relationship.

In the domain occupational activity, pain $(\beta=-13.30$; $\mathrm{p}=0.0358)$, emotional reaction $(\beta=-14.73 ; \mathrm{p}=0.0171)$ were statistic important in the non-working group.

Blood pressure and heart rate control was statistically important in the group of patients with every day selfcontrol $(\beta=-20.24 ; \mathrm{p}=0.0375)$, and patients who rarely had self-control $(\beta=-19.18 ; p=0.0445)$. This means that a higher QoL is characteristic for these 2 groups of patients.

BMI was statistically important in 5 domains, except sleep disorders. In each of the 5 domains: energy $(\beta=2.24$; $\mathrm{p}=0.0024)$, pain $(\beta=1.43 ; \mathrm{p}=0.0146)$, emotional reaction $(\beta=1.15 ; p=0.0433)$, social isolation $(\beta=1.51 ; p=0.0050)$, and mobility restrictions $(\beta=0.94 ; \mathrm{p}=0.0453)$, QoL was lower for people with a higher BMI.

Physical activity (mixed / activity lifestyle) and higher QoL, positively influenced energy $(\beta=-29.96 ; p=0.0007 / \beta=$ -35.50; $p=0.0057)$, feeling pain $(\beta=-20.48 ; p=0.0034 / \beta=-$ $25.55 ; \mathrm{p}=0.0127)$, emotional reaction $(\beta=-21.91 ; \mathrm{p}=0.0013$ $/ \beta=-33.62, p=0.0009)$, and mobility restrictions $(\beta=-14.79$; $\mathrm{p}=0.0086 / \beta=-22.68 ; \mathrm{p}=0.0064)$.

\section{DISCUSSION}

Diseases of the cardiovascular system are the main cause of premature deaths in the majority of countries [1]. In Poland, they are the most frequent cause of hospitalizations and 
Table 3. Level of impairment of life function by questionnaire NHP

\begin{tabular}{|c|c|c|c|c|c|c|}
\hline & Energy (NHP) & Pain (NHP) & $\begin{array}{c}\text { Emotional reaction } \\
(\mathrm{NHP})\end{array}$ & $\begin{array}{l}\text { Sleep disorders } \\
(\mathrm{NHP})\end{array}$ & $\begin{array}{l}\text { Social isolation } \\
\text { (NHP) }\end{array}$ & $\begin{array}{c}\text { Mobility restrictions } \\
\text { (NHP) }\end{array}$ \\
\hline \multicolumn{7}{|l|}{ Gender } \\
\hline Female $(n=41)$ & $54.4 \pm 37.8$ & $25.4 \pm 29.6$ & $34.6 \pm 28.6$ & $51.7 \pm 39.3$ & $24.8 \pm 29.3$ & $38.2 \pm 24.5$ \\
\hline Male $(n=59)$ & $43.0 \pm 40.8$ & $26.1 \pm 27.1$ & $32.5 \pm 28.2$ & $41.4 \pm 37.7$ & $20.9 \pm 28.9$ & $31.3 \pm 27.9$ \\
\hline $\mathrm{p}$-value & 0.1000 & 0.7777 & 0.8079 & 0.1717 & 0.3705 & 0.1404 \\
\hline \multicolumn{7}{|l|}{ Age } \\
\hline $45-54$ & $21.1 \pm 28.7$ & $20.1 \pm 35.4$ & $27.3 \pm 27.7$ & $23.2 \pm 29.6$ & $7.6 \pm 17.6$ & $11.9 \pm 17.2$ \\
\hline $55-64$ & $33.1 \pm 31.5$ & $15.8 \pm 23.3$ & $22.5 \pm 19.9$ & $32.2 \pm 28.9$ & $7.6 \pm 15.8$ & $24.3 \pm 23.5$ \\
\hline $65-74$ & $67.0 \pm 41.3$ & $33.8 \pm 26.5$ & $46.6 \pm 32.8$ & $55.2 \pm 41.4$ & $43.8 \pm 34.2$ & $43.6 \pm 26.7$ \\
\hline $75-84$ & $60.4 \pm 37.6$ & $30.4 \pm 22.2$ & $34.4 \pm 26.5$ & $80.0 \pm 31.0$ & $30.3 \pm 22.5$ & $52.4 \pm 13.3$ \\
\hline $85-94$ & $100.0 \pm 0.0$ & $80.3 \pm 0.0$ & $53.0 \pm 0.0$ & $12.6 \pm 0.0$ & $0.0 \pm 0.0$ & $78.7 \pm 0.0$ \\
\hline $\mathrm{p}$-value & $<0.0001$ & $<0.0001$ & 0.0028 & $<0.0001$ & $<0.0001$ & $<0.0001$ \\
\hline \multicolumn{7}{|l|}{ Education } \\
\hline primary $(n=10)$ & $69.1 \pm 30.1$ & $40.3 \pm 25.4$ & $34.3 \pm 16.5$ & $58.9 \pm 45.2$ & $22.2 \pm 30.9$ & $53.9 \pm 29.4$ \\
\hline vocational $(n=37)$ & $64.2 \pm 39.6$ & $37.9 \pm 33.7$ & $42.5 \pm 27.0$ & $51.9 \pm 39.7$ & $30.1 \pm 32.5$ & $44.9 \pm 25.1$ \\
\hline secondary $(n=30)$ & $41.2 \pm 39.3$ & $15.3 \pm 17.5$ & $35.2 \pm 34.9$ & $52.8 \pm 36.2$ & $22.1 \pm 29.8$ & $29.4 \pm 23.2$ \\
\hline higher $(n=23)$ & $20.2 \pm 25.3$ & $13.9 \pm 19.0$ & $15.9 \pm 14.8$ & $20.4 \pm 25.5$ & $11.0 \pm 16.0$ & $14.5 \pm 17.6$ \\
\hline p-value & 0.0001 & 0.0003 & 0.0045 & 0.0031 & 0.2285 & $<0.0001$ \\
\hline \multicolumn{7}{|l|}{ Marital status } \\
\hline single $r(n=41)$ & $98.2 \pm 34.5$ & $45.6 \pm 36.2$ & $144.2 \pm 29.8$ & $105.5 \pm 57$ & $91.2 \pm 49.0$ & $82.8 \pm 32.5$ \\
\hline In relationship $(\mathrm{n}=59)$ & $34.8 \pm 36.4$ & $20.2 \pm 27.1$ & $23.1 \pm 26.6$ & $32.9 \pm 34.4$ & $6.0 \pm 13.4$ & $25.4 \pm 26.3$ \\
\hline$\underline{p \text {-value }}$ & 0.0001 & 0.0002 & 0.0001 & 0.0001 & 0.0001 & 0.0001 \\
\hline \multicolumn{7}{|l|}{ Occupational activity } \\
\hline unemployed $(n=62)$ & $61.8 \pm 38.0$ & $35.6 \pm 29.5$ & $41.1 \pm 28.0$ & $55.6 \pm 38.7$ & $25.7 \pm 28.8$ & $45.3 \pm 24.5$ \\
\hline working $(n=38)$ & $24.6 \pm 31.3$ & $10.0 \pm 15.8$ & $20.8 \pm 24.0$ & $29.3 \pm 32.5$ & $17.4 \pm 29.0$ & $16.0 \pm 19.3$ \\
\hline$\underline{p \text {-value }}$ & $<0.0001$ & $<0.0001$ & 0.0003 & 0.0004 & 0.0467 & $<0.0001$ \\
\hline rarely self-control $(n=31)$ & $46.5 \pm 39.2$ & $22.6 \pm 26.2$ & $28.4 \pm 26.3$ & $47.2 \pm 36.8$ & $15.4 \pm 23.9$ & $34.1 \pm 25.6$ \\
\hline $\begin{array}{l}\text { during an appointment at a } \\
\text { doctor }(n=19)\end{array}$ & $79.3 \pm 35.1$ & $43.9 \pm 31.4$ & $48.4 \pm 27.3$ & $52.4 \pm 42.1$ & $34.5 \pm 28.6$ & $51.6 \pm 23.5$ \\
\hline$\underline{p \text {-value }}$ & 0.0008 & 0.0040 & 0.0169 & 0.4293 & 0.0406 & 0.0051 \\
\hline \multicolumn{7}{|l|}{ BMI } \\
\hline $18.5-24.99$ & $37.3 \pm 34.8$ & $12.3 \pm 16.2$ & $22.8 \pm 19.5$ & $33.7 \pm 36.3$ & $19.0 \pm 26.5$ & $22.8 \pm 23.6$ \\
\hline $25.0-29.99$ & $43.5 \pm 43.1$ & $29.3 \pm 33.2$ & $32.3 \pm 27.5$ & $47.1 \pm 35.6$ & $9.1 \pm 17.9$ & $36.2 \pm 28.5$ \\
\hline $30.0-34.99$ & $45.1 \pm 31.5$ & $35.2 \pm 32.1$ & $33.0 \pm 30.2$ & $37.6 \pm 38.3$ & $24.2 \pm 25.6$ & $40.5 \pm 23.5$ \\
\hline$\geq 35.0$ & $100.0 \pm 0.0$ & $37.8 \pm 13.0$ & $71.0 \pm 16.8$ & $93.9 \pm 10.4$ & $74.3 \pm 8.2$ & $51.7 \pm 22.1$ \\
\hline$\underline{p \text {-value }}$ & 0.0016 & 0.0001 & 0.0009 & 0.0085 & 0.0010 & 0.0013 \\
\hline \multicolumn{7}{|l|}{ Physical activity } \\
\hline sedentary lifestyle $(n=23)$ & $91.7 \pm 22.9$ & $51.4 \pm 28.7$ & $56.6 \pm 26.4$ & $71.5 \pm 38.9$ & $31.6 \pm 30.9$ & $61.5 \pm 20.7$ \\
\hline Mixed lifestyle $(n=51)$ & $43.2 \pm 35.3$ & $21.7 \pm 24.6$ & $32.7 \pm 27.8$ & $46.9 \pm 35.3$ & $27.1 \pm 30.0$ & $33.0 \pm 21.0$ \\
\hline Aktive lifestyle $(n=26)$ & $17.4 \pm 23.6$ & $11.4 \pm 17.9$ & $14.2 \pm 11.1$ & $20.2 \pm 27.5$ & $5.5 \pm 16.3$ & $12.2 \pm 19.2$ \\
\hline p-value & $<0.0001$ & $<0.0001$ & $<0.0001$ & $<0.0001$ & $<0.0001$ & $<0.0001$ \\
\hline
\end{tabular}

permanent incapacity for work. Analysis of QoL evaluated in what way occurrence of the disease and the limitations related to it affected the functioning of patients in everyday life [13].

Own research proved that QoL of patients after a myocardial infarction deteriorates in many areas. The degree of its deterioration, as demonstrated by the results of the current study, depends on socio-demographic factors, such as: age, education, marital status or professional activity. The participation of clinical factors, such as physical activity or the occurrence of comorbidities (obesity, arterial hypertension), in the shaping of the level of QoL was also significant.

Research by the authors of this study have demonstrated the very important influence of age on the QoL of a patient. It was proved that the older the person, the higher the level of impairment in all areas of life. This corresponds with the results obtained by Pałczak et al. [14] who evaluated QoL using the SF-36 questionnaire in a PCS group (domains of physical activity - Physical Component Scale). A statistically significant negative correlation was observed which proved that elderly people evaluate their QoL as worse.

Similar results were obtained by Uchmanowicz et al. [7] during examination of QoL 6 months after myocardial infarction, also using the SF-36 questionnaire. The authors demonstrated that QoL among patients over 65 
Table 4. Multiple linear regression models with the 6 dimensions of NHP (energy, pain, emotional reactions, sleep, social isolation, physical mobility) as dependent variables, and socio-demographic and clinical data as independent variables

\begin{tabular}{|c|c|c|c|c|c|c|c|c|c|c|c|c|}
\hline & \multicolumn{2}{|c|}{ Energy (NHP) } & \multicolumn{2}{|c|}{ Pain (NHP) } & \multicolumn{2}{|c|}{$\begin{array}{l}\text { Emotional } \\
\text { reaction (NHP) }\end{array}$} & \multicolumn{2}{|c|}{$\begin{array}{c}\text { Sleep disorders } \\
\text { (NHP) }\end{array}$} & \multicolumn{2}{|c|}{$\begin{array}{c}\text { Social isolation } \\
\text { (NHP) }\end{array}$} & \multicolumn{2}{|c|}{$\begin{array}{c}\text { Mobility } \\
\text { restrictions (NHP) }\end{array}$} \\
\hline & $\mathrm{B}$ & $\mathrm{p}$-value & B & $\mathrm{p}$-value & $\mathrm{B}$ & $\mathrm{p}$-value & $\beta$ & $\mathrm{p}$-value & $\beta$ & p-value & $\beta$ & $\mathrm{p}$-value \\
\hline Age (years) & -0.04 & 0.9212 & 0.03 & 0.9302 & -0.83 & 0.0146 & 0.22 & 0.6572 & -0.11 & 0.7140 & 0.88 & 0.0021 \\
\hline \multicolumn{13}{|l|}{ Education } \\
\hline Primary $(n=10)$ & - & - & - & - & - & - & - & - & - & - & - & - \\
\hline vocational $(n=37)$ & 1.35 & 0.9033 & -1.69 & 0.8492 & 8.29 & 0.3387 & -0.25 & 0.9846 & 7.42 & 0.3600 & 0.42 & 0.9535 \\
\hline secondary $(n=30)$ & -7.93 & 0.4973 & -14.89 & 0.1139 & 11.43 & 0.2100 & 9.83 & 0.4747 & 5.36 & 0.5288 & -6.21 & 0.4127 \\
\hline high $(n=23)$ & -14.44 & 0.2527 & -7.52 & 0.4561 & 1.92 & 0.8441 & -13.48 & 0.3631 & 1.67 & 0.8552 & -11.66 & 0.1549 \\
\hline \multicolumn{13}{|l|}{ Marital status } \\
\hline single $(n=41)$ & - & - & - & - & - & - & - & - & - & - & - & - \\
\hline partnership $(n=59)$ & -2.62 & 0.7267 & 4.22 & 0.4833 & -16.34 & 0.0061 & -18.43 & 0.0389 & -35.88 & $<0.0001$ & 1.04 & 0.8302 \\
\hline \multicolumn{13}{|l|}{ Occupational activity } \\
\hline Working $(n=62)$ & - & - & - & - & - & - & - & - & - & - & - & - \\
\hline Not woring $(n=38)$ & -14.86 & 0.0597 & -13.30 & 0.0358 & -14.73 & 0.0171 & -13.23 & 0.1521 & 2.79 & 0.6241 & -7.75 & 0.1285 \\
\hline \multicolumn{13}{|c|}{ Blood pressure and heart rate control } \\
\hline Can't do alone $(\mathrm{n}=19)$ & - & - & - & - & - & - & - & - & - & - & - & - \\
\hline Everyday self-control $(n=50)$ & -20.24 & 0.0375 & -1.00 & 0.8962 & -0.68 & 0.9271 & 17.71 & 0.1193 & -1.27 & 0.8555 & 3.59 & 0.5640 \\
\hline Rarely self-control $(n=30)$ & -19.18 & 0.0445 & -7.26 & 0.3382 & -9.77 & 7.32 & 16.25 & 0.1453 & -5.76 & 0.4022 & 2.22 & 0.7165 \\
\hline BMI & 2.24 & 0.0024 & 1.43 & 0.0146 & 1.15 & 0.0433 & 0.81 & 0.3410 & 1.51 & 0.0050 & 0.94 & 0.0453 \\
\hline \multicolumn{13}{|l|}{ Physical activity } \\
\hline Sedentary lifestyle $(n=51)$ & -29.96 & 0.0007 & -20.48 & 0.0034 & -21.91 & 0.0013 & -17.44 & 0.0839 & 5.17 & 0.4048 & -14.79 & 0.0086 \\
\hline Active lifestyle $(n=26)$ & -35.50 & 0.0057 & -25.55 & 0.0127 & -33.62 & 0.0009 & -27.26 & 0.0677 & -2.62 & 0.7744 & -22.68 & 0.0064 \\
\hline Adjusted square $R$ & & 0.57 & & 0.44 & & 0.49 & & 0.37 & & 0.57 & & 0.60 \\
\hline
\end{tabular}

was significantly worse compared to a younger group of patients. Other studies carried out by Kowman et al. [15] showed a similar correlation. It was concluded that increasing age negatively affects the assessment of QoL due to the deterioration of physical capacity.

Brown et al. [16] in a study conducted by the SF-36 questionnaire on 424 patients 4 years after myocardial infarction, found that age affected QoL in all 8 domains.

Patients aged under 65 years exhibited impairment in all 8 domains, the largest differences being in physical functioning, physical role and general health. Multiple regression analysis revealed that impaired QoL was closely associated with the inability to return to work through ill health. In patients aged over 65, the mean domain scores were similar to norms. However, a different situation was presented by Kwaśniewska et al. [17] who argued that age has no influence on QoL.

The current research indicates a significant influence of education as a predicator of QoL. Observations made by Uchmanowicz et al. [7] indicated that higher education positively affected QoL of patients in many of its domains. Very interesting conclusions were obtained by Wilski [18] while investigating a group of 25 women and 52 men 2-4 months after a myocardial infarction, and subjected to cardiac rehabilitation. The surveyed patients filled in the questionnaires measuring the level of readiness for entering the process of rehabilitation and the level of acceptance of their own disability. The results showed that those with higher education demonstrated a significantly higher level of readiness for rehabilitation, which indicated a greater awareness of their own health status, and greater awareness of the consequences of not undertaking the rehabilitation.
Differing conclusions were obtained by Pałczak et al. [14] who did not demonstrate the influence of education on QoL.

Research by the authors of the presented study revealed the significant influence of education on almost all the life domains, except social isolation. It was proved that people with primary and secondary education demonstrated a higher level of impairment in particular domains when compared with people with higher education. Similar results have also been obtained by other authors $[1,19-20]$.

Marital status is another predicator affecting QoL of the patients. Pałczak et al. [14] observed that people in relationships evaluate QoL in the physical activity domain better than those who are single. These results are compliant with those obtained by Kwaśniewska et al. [17]. They also correspond with the results of the own studies which indicated that the worst QoL occured among widowers and single people. Luttik et al. [21] also confirmed that inferior QoL and recurrent episodes of deterioration occurred in single persons, mostly elderly women with a low socioeconomic status. Similar data were also obtained by other authors $[1,22]$.

Another factor significantly reducing QoL in this study is a high body mass index (BMI). Similar conclusions were obtains by Kwaśniewska et al. [17], according to whom patients with BMI below $30 \mathrm{~kg} / \mathrm{m} 2$ evaluated their life standard much better. The problem of overweight and obesity has also been highlighted by Mizia et al. [23], who noted that in Polish society these issues constitute a serious problem which is additionally compounded by improper eating habits and an unfavorable physical activity profile.

Regular physical effort among people with coronary artery disease increases the effectiveness of the supply of oxygen, improves the metabolism of skeletal muscles, increases 
the sensitivity to insulin and fibrinolytic activity of the blood plasma, it modifies the lipid metabolism, leads to the lowering of the blood pressure and to the reduction of body mass, it lowers the heart rate, increases the diameter of the blood vessels and improves their motility, it enhances the development of collateral circulation, improves the mood and has a calming effect. All these benefits of physical effort indicate a great need for the education of patients in this field, and the necessity for continuous improvement, popularization and encouraging patients, especially to cardiac rehabilitation [24].

Well-planned and performed rehabilitation is considered one of the most important methods for improving QoL of patients after a myocardial infarction. Sometimes, without extraordinary effects on the scope of the clinical condition, the rehabilitated patients declare noticeable signs of improvement in their daily functioning. Interesting conclusions have been reached by Pałuk et al. [24] while performing studies in 2008 among a group of 64 patients in the Cardiology SubDepartment of the Internal Medicine Department of the Fryderyk Chopin Regional Specialist Hospital in Rzeszów. The patients were divided into 2 groups. The first included 32 people after a myocardial stroke, and the second group - the control group - included 32 people. The main group was examined twice - first after diagnosing the myocardial infarction and during the implementation of the $1^{\text {st }}$ stage of the rehabilitation. The second examination took place at the end of the $2^{\text {nd }}$ stage of the rehabilitation. While comparing the results of the examinations carried out with the help of the NHP questionnaire among patients after a myocardial infarction, at the end of the rehabilitation period significant improvement of QoL was found in each of the domains.

Kupcewicz et al. [25] in their studies using the SF-36 questionnaire on 80 patients after myocardial infarction, showed that gender, age, education, disability level, support of family and friends affect QoL in the physical domain. However, QoL of the patients in the domain of mental health, was determinated by age, education, duration of the disease, self-control of blood pressure, family support, use of medical advice, and preventive measures related to systematic research.

The research showed the areas of life in which the patients reported the highest number of disorders and problems which definitely affected QoL. In view of the obtained results, it seems reasonable to examine the influence of other factors that may affect QoL of patients after myocardial infarction, such as socio-economic status, sleep disorders, additional medical burden, or the need to take many medications.

\section{CONCLUSIONS}

1. The significant independent determinants of lower QoL were old age and BMI, whereas being in a relationship, physical activity and occupational inactivity, were important determinants of higher QoL scores.

2. It is necessary to ensure the early implementation of health education aimed at modifying lifestyle and cardiac rehabilitation which significantly improve the functioning of patients who have undergone myocardial infarction.

\section{REFERENCES}

1. Durmaz T, Özdemir Ö, Özdemir B.A, Keleș T, Bayram NA, Bozkurt E: Factors affecting quality of life in patients with coronary heart disease. Turk J Med Sci. 2009; 39(3): 343-51.

2. Paciorek M, Sochocka L. The impact of myocardial infarction on the lifestyle and well-being of patients. Care and clinical aspects of care for patients. $1^{\text {st }}$ ed. Continuo, 2012, pp.101-108.

3. Talarska D. Prevention of cardiovascular diseases. Cardiac nursing. 1st ed. Lek. PZWL, Warszawa; 2011 pp. 27-43.

4. Mancia G, Laurent S, Agabiti-Rosei E, et al. Reappraisal of European guidelines of hypertension management: A European Society of Hypertension Task Force document. J Hypertens. 2009; 27: 2121-2158.

5. Michajlik A. The concept of risk factors. Guidance book. 1st ed. Lek. PZWL, Warszawa; 2005, pp. 24-56.

6. Hambrecht R, Wolf A, Gielen S, i wsp. Effect of exercise on coronary endothelial function in patients with coronary artery disease. $\mathrm{N}$ Engl J Med. 2007; 342: 454-460.

7. Uchmanowicz I, Łoboz-Grudzień K, Jankowska-Polańska B, Sokalski L. Influence of diabetes on health-related quality of life results in patients with acute coronary syndrome treated with coronary angioplasty. Acta Diabetol. 2013; 50(2) :217-25.

8. Mędrela-Kuder E. Anti-healing behaviors of patients with myocardial infarction. Med Sport. 2010; 26(4): 178-186.

9. Dąbrowska J, Jurek A, Krakowska A, Grąbczewska Z, Kubica A. Participation of the sick family in the rehabilitation of people after a heart attack. Cardiovasc Forum. 2007; 12(1/2): 18-22.

10. Hunt SM, McKenna SP, McEwen J, Backett EM, Williams J, Papp E. A quantitative approach to perceived health status: A validation study. J Epidemiol Community Health. 1980; 34(4): 281-6.

11. The European Group for Quality of Life and Health Measurement. European Guide to the Nottingham Health Profile. Montpellier 1992.

12. Wrzesniewski K. Examining the subjective health status using the Polish adaptation of the Nottingham Health Profile In: Karski J.B, Kirschner H, Leowski J. (eds.). Contemporary needs and possibilities of health measurement. Krajowa Konferencja Naukowa: Warszawa pp. 37-41; 1997.

13. Kubica J, Sinkiewicz W. Chory po zawale serca. Via Medica, 1st ed. Gdańsk, 2008.

14. Pałczak E, Uchmanowicz I. Analysis of factors affecting the quality of life after myocardial infarction. Piel Zdr Publ. 2012; 2(1): 29-37.

15. Kowman M, Sobów T, Kłoszewska I. Anxiety and anxiety disorders in heart disease. Wiad psychiatr. 2007; X: 2.

16. Brown N, Melville M, Gray D, Young T, Munro J, Skene AM, Hampton JR. Quality of life four years after acute myocardial infarction: short form 36 scores compared with a normal population. Heart. 1999; 81(4): 352-8.

17. Kwaśniewska M, Drygas W. Quality of life in patients with risk factors of coronary heart disease. Przegląd Lekarski. 2005; 62(9): 863-870.

18. Wilski M. The relationship between the acceptance of one's disability and the rehabilitation readiness of patients after heart attacks. Post Rehab. 2006; (4): 39-45.

19. Verrill D, Barton C, Beasley W, Brennan M, Lippard M, King C. Quality of life measures and gender comparisons in North Carolina Cardiac Rehabilitation Programs. J Cardiopulm Rehabil. 2001; 21(1): 37-46.

20. Luckarinen H, Hentinen M. Assesment of quality of life the Nottingham health profile among patients with coronary heart disease, J Adv Nurs. 1997; 26(1): 73-84.

21.Luttik ML, Jaarsma T, Veeger N, van Veldhuisen DJ. Marital status, quality of life, and clinical outcome in patients with heart failure. Heart Lung. 2006; 35: 3-8.

22. Christian AH, Cheema AF, Smith SC, Mosca L. Predictors of quality of life among women with coronary heart disease. Qual Life Res. 2007; 16: 363-73.

23. Mizia-Stec K, Kańczuga K, Zwolińska W, Kumor P, Niedojadło-Kumor A, Gąsior Z. Patients after the first myocardial infarction in distant observation. Ann Acad Med Siles. 2006; 60: 6.

24. Pałuk W, Jakubowski K. Evaluation of the impact of cardiac rehabilitation on the quality of life of people after myocardial infarction. Pielęgniarstwo XXI wieku. 2008. 45-51.

25. Kupcewicz E, Sawlewicz M. Socio-demographic and medical determinants of the quality of life in patients after myocardial infarction. Balt J Health Phys Act. 2017; 9(2): 73-81. 